\title{
Liposome and Polysaccharide Based Nanomedicines: An Emerging Hope to Improve the Peritoneal Dialysis Technique
}

\section{Guleria A and Kumar D}

Centre of Biomedical Research (CBMR), Lucknow-226014, Uttar Pradesh, India

"Corresponding author: Kumar D, Centre of Biomedical Research (CBMR), SGPGIMS Campus, Raibareli Road, Lucknow-226014, Uttar Pradesh, India, Tel: +91-8953261506, 8005409932; E-mail: dineshcbmr@gmail.com

Received date: November 03, 2016; Accepted date: December 08, 2016; Published date: December 12, 2016

Copyright: (c) 2016 Guleria A, et al. This is an open-access article distributed under the terms of the Creative Commons Attribution License, which permits unrestricted use, distribution, and reproduction in any medium, provided the original author and source are credited.

Keywords: Polysaccharide based Nanoparticles; Antimicrobial nanomaterials; Biological synthesis; Peritoneal dialysis; Renal replacement therapy; Health care infections; Infectious peristonitis

\section{Introduction}

Peritoneal Dialysis (PD) is the simple and cost-effective renal replacement modality used for treating patients with End-Stage Renal Failure (ESRF) [1-3]. It offers several clear advantages over Hemodialysis (HD) like cost-effectiveness, flexibility and autonomy to the patients, however, it is often associated with a high risk of infection of the peritoneal cavity, subcutaneous tunnel and catheter exit site as well as the subsequently formed microbial biofilms. In current practice, the episodes of PD associated infections-if diagnosed timely-are cured through the empirical use of antibiotics. However, the fungal infections or infections caused by drug resistant bacteria remains critical and often lead to inflammation of the peritoneum. The complicationgenerally known as infectious peritonitis-is not only the major cause of technique failure and patient transferring to $\mathrm{HD}$, it is also the leading cause of mortality and morbidity in ESRF patients continuing on PD. As the number of ESRF patients continuing on PD is increasing continuously every year, the $\mathrm{PD}$ associated infections are also becoming more and more evident posing extra burden on dialysiscenters/nephrology-wards to resolve such life-threatening and critical conditions. The situation is even more pathetic and worse in developing countries-having limited healthcare centers and poor socioeconomic status of patients-where majority of ESRF patients continuing on PD die because of intraperitoneal (IP) infections [1,3-5]. As ESRF patients are generally manifested with sabotaged immune system, therefore, high antibiotic dose is often used to achieve complete eradication of Intraperitoneal (IP) infections. However, the frequent intraperitoneal administration of higher anti-biotic doses may cause serious side-effects including peritoneal malfunctioning and hepatotoxicity. Thus, there has been an urgent need to improve the PD technique in terms of reducing the frequency of IP infections and improving its efficiency to remove drugs/endotoxins from the patient body.

\section{Nanomedicines}

There are several reports in the literature now where nanotechnology products including nanomedicines have been implicated in the diagnosis and treatment of kidney diseases [6]. There is also an increasing cohort of nanomaterials which has been envisaged to improve the PD technique either through the use of (a) antimicrobial spray for preventing Catheter Exit-Site Infection [7], (b) liposomes for detoxification of drugs and endogenous metabolites to enhance the efficiency of peritoneal dialysis $[8,9]$, (c) nano-carriers for
TNF- $\beta 1$-SiRNA to inhibit the peritoneal fibrosis [10], (d) silicacontaining redox nanoparticles (siRNPs) for high-performance peritoneal dialysis through suppressing oxidative stress by scavenging Reactive Oxygen Species [11], and (e) antimicrobial nanomaterials synthesized biologically-which confer several advantages like biocompatibility, low cellular toxicity and activity against variety of drug-resistant bacteria- to impart infection resistant properties to the $\mathrm{PD}$ fluid and thus reducing the frequency of $\mathrm{PD}$ associated infections [12]. An alternative, but more relevant and promising approach to improve the existing PD therapy-in terms of its dialysis efficiency and limiting microbial infections- can be envisaged based on the use of liposomal antibiotic formulations [13,14]. Liposomes-generally referred as nanometric size vesicles formed by phospholipid bilayer membrane-exhibit remarkable physicochemical properties like biocompatibility, biodegradability, and low cytotoxicity. On top of this, these (a) may increase the solubility of hydrophilic, hydrophobic and amphiphilic molecules of therapeutic potential, (b) may protect them from degradation in the body and (c) may enhance their retention time within the peritoneal cavity [13-16]. All these features are highly desirable for increasing dialysis efficiency and treatment against of formidable intraperitoneal infections in PD patients. Therefore, we strongly believe that liposomal formulations will soon enter into the peritoneal dialysis therapy: (a) to reduce the in vivo toxicity of antibiotics for their safe intraperitoneal use and/or (b) to improve the therapeutic efficacy of poorly water soluble antibiotics $[13,16]$. Similarly, the nanometric drug-delivery systems derived from natural polysaccharides -such as heparin, cellulose, chitin, chitosan, cyclodextrin, dextrose, etc. can also be envisaged for effective and complete eradication of IP infections [17-22]. Natural polysaccharides represent a novel class of permeative biopolymers and because of their stability, availability, renewability, low toxicity and low cost are gaining tremendous popularity in the development of nano-sized drug delivery systems [23]. Various functional groups such as hydroxyl, amine etc. which are present in these polysaccharides allows chemical derivatization by which their properties can be modulated and adjusted to the aimed application [23-25]. These are the reasons that polysaccharides based biomaterials have undergone rapid development in the past few decades for their use in a variety of biomedical and pharmaceutical applications such as drug delivery (or co-delivery of synergistic drug combinations), gene therapy, vascular grafts, and scaffolds for tissue engineering, wound dressings, medical implants and medical imaging [17,22]. In the context of improving PD technique, we foresee a great potential of low molecular weight heparin based nano-sized drug delivery systems. Heparin-most commonly known as an anticoagulant-is commonly administered intraperitoneally whenever fibrin is detected in the dialysate effluent (a clinical manifestation of peritonitis) [26]. A variety of recent research studies have shown that heparin improves the biocompatibility of 
nanoparticles; thus improve their performance in various biological applications [24]. It is believed that there is no absorption of heparin across the peritoneal cavity and is almost risk-free [26]. This belief, coupled with its remarkable biological activity (including antimicrobial [27], anti-inflammatory [28] and ability to mitigate oxidative stress $[29,30])$ derived our interest to write this commentary and introduce the PD community about the possibility of using Heparin based nanoparticle systems in addition to liposome based formulations for improving the PD technique.

Overall, we appraise the necessity to improve the existing PD technique for limiting frequency of intraperitoneal infections during long-term PD therapy and the possibility to achieve this through the applications of liposomal and polysaccharide based Antimicrobial Nanomedicines (ANMs) (Figure 1). This indeed would require conscience preclinical and clinical efforts to assess the dose dependent in vivo toxicity of such ANMs when injected intraperitoneally followed by evaluation of their efficacy at biologically safe doses against variety of microbial infections including fungal and multidrug resistant bacteria. Further to ensure their safe and long-term intraperitoneal use, time dependent evaluation of their efficacy and adequacy (i.e., biocompatibility and non-cytotoxicity) would also be essential.

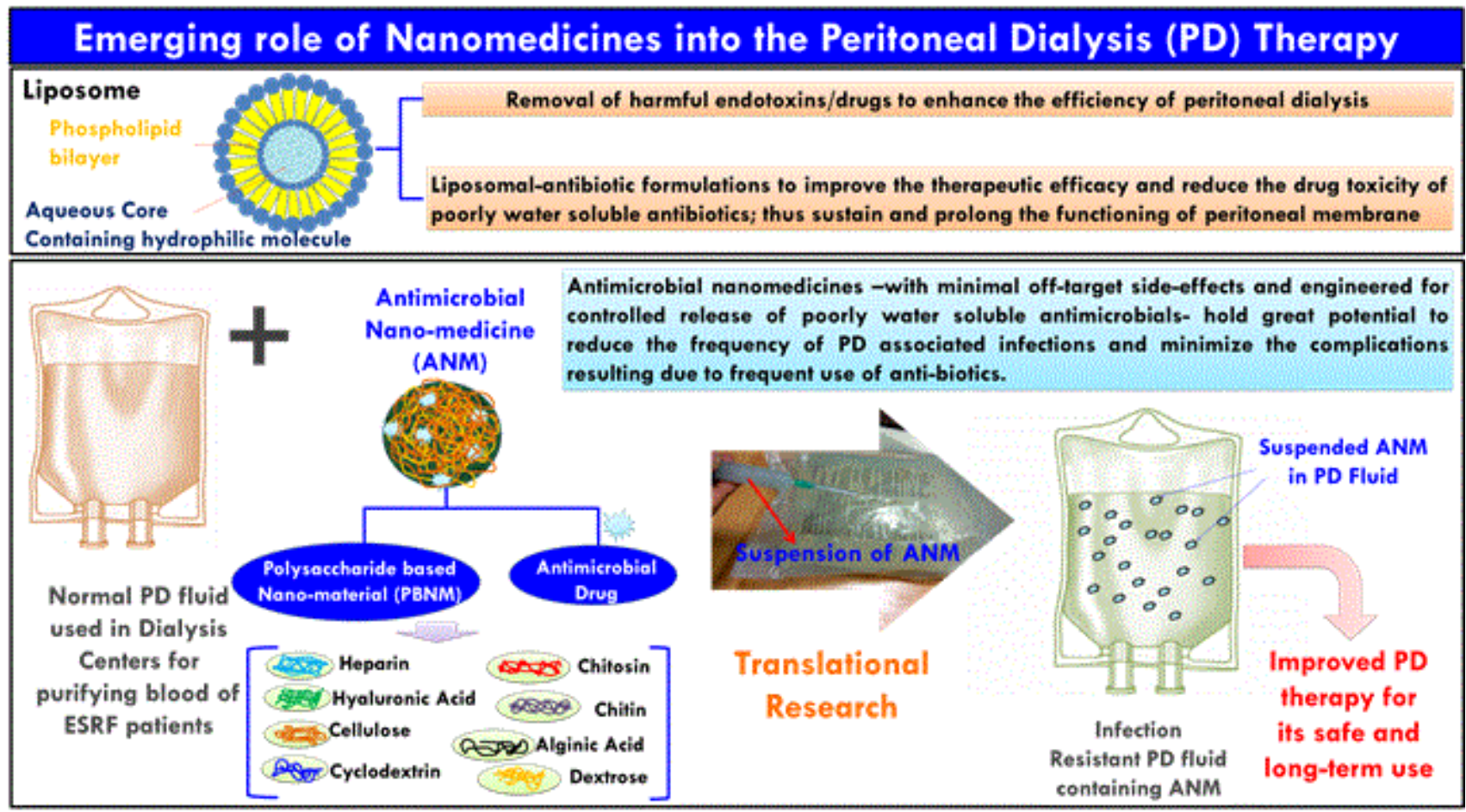

Figure 1: Pictorial illustration showing possibility to improve the peritoneal dialysis technique through the use of liposomal and polysaccharide based nanomedicines.

\section{Acknowledgement}

We would like to acknowledge Dr. Poluri Krishna Mohan (Department of Biotechnology and Centre for Nanotechnology, Indian Institute of Technology Roorkee, Roorkee 247667, Uttarakhand, India), Dr. Narayan Prasad (Department of Nephrology, SGPGIMS, Lucknow, India), Dr. V Karthick (Nanoscience Division, Centre for Ocean Research, Sathyabama University, Chennai, India) and Dr. Sudipta Saha (Department of Pharmaceutical Sciences, Babasaheb Bhimrao Ambedkar University, Vidya Vihar, Raibareli Road, Lucknow, India) for all their useful suggestions and critical comments while preparing this commentary.

\section{References}

1. Akoh JA (2012) Peritoneal dialysis associated infections: An update on diagnosis and management. World J Nephrol 1: 106-122.

2. Gokal R, Mallick NP (1999) Peritoneal dialysis. Lancet 353: 823-828.
3. Li PT, Szeto CC, Piraino B, Bernardini J, Figueiredo AE, et al. (2010) ISPD Guidelines/Recommendations: Peritoneal Dialysis-Related Infections Recommendations (2010 Update). Perit Dial Int 30: 393-423.

4. Xu R, Han QF, Zhu TY, Ren YP, Chen JH, et al. (2012) Impact of individual and environmental socioeconomic status on peritoneal dialysis outcomes: a retrospective multicenter cohort study. PLoS ONE 7: e50766.

5. Fontan MP, Rodriguez-Carmona A, Garcia-Naveiro R, Rosales M, Villaverde P, et al. (2005) Peritonitis-related mortality in patients undergoing chronic peritoneal dialysis. Perit Dial Int 25: 274-284.

6. Williams RM, Jaimes EA, Heller DA (2016) Nanomedicines for kidney diseases. Kidney Int 90: 740-745.

7. Tam BML, Chow SKY (2014) A preliminary report on the effectiveness of Nanotechnology Anti-Microbial Spray Dressing in preventing tenckhoff Catheter exit-Site Infection. Perit Dial Int 34: 670-673

8. Devuyst O, Schumann A (2015) Peritoneal Dialysis: Nanoparticles Have Entered the Game. Perit Dial Int 35: 240.

9. Forster V, Signorell RD, Roveri M, Leroux JC (2014) Liposome-supported peritoneal dialysis for detoxification of drugs and endogenous metabolites. Sci Trans Med 6: 258ra141. 
10. Yoshizawa H, Morishita $\mathrm{Y}$, Watanabe M, Ishibashi K, Muto S, et al. (2015) TGF-B1-siRNA delivery with nanoparticles inhibits peritoneal fibrosis. Gene Ther 22: 333-340.

11. Nagasaki Y, Yaguchi T, Matsumura T, Yoshitomi T, Ikeda Y, et al. (2014) Design and use of silica-containing redox nanoparticles, siRNPs, for high-performance peritoneal dialysis. Biomat Sci 2: 522-529.

12. Kumar D (2016) Use of biologically synthesized antimicrobial nanoparticles for improving peritoneal dialysis technique: a translational research perspective. J Biomed Res 30: 349-352.

13. Alipour M, Suntres ZE (2014) Liposomal antibiotic formulations for targeting the lungs in the treatment of Pseudomonas aeruginosa. Ther Deliv 5: 409-427.

14. Drulis-Kawa Z, Dorotkiewicz-Jach A (2010) Liposomes as delivery systems for antibiotics. Int J Pharm 387: 187-198.

15. Peer D, Karp JM, Hong S, Farokhzad OC, Margalit R, et al. (2007) Nanocarriers as an emerging platform for cancer therapy. Nat Nanotechnol 2: 751-760.

16. Shimanovich U, Gedanken A (2016) Nanotechnology solutions to restore antibiotic activity. J Mater Chem B 4: 824-833.

17. Swami A, Shi J, Gadde S, Votruba A, Kolishetti N, et al. (2012) Nanoparticles for Targeted and Temporally Controlled Drug Delivery. Multifunctional Nanoparticles for Drug Delivery Applications. Springer US: 9-29.

18. Singh R, Lillard J (2009) Nanoparticle-based targeted drug delivery. Exp Mol Pathol 86: 215-223.

19. Liu Z, Jiao Y, Wang Y, Zhou C, Zhang Z (2008) Polysaccharides-based nanoparticles as drug delivery systems. Adv Drug Deliv Rev 60: 1650-1662.
20. Lin N, Dufresne A (2014) Nanocellulose in biomedicine: Current status and future prospect. Eur Polym J 59: 302-325.

21. Kumar MN, Muzzarelli RA, Muzzarelli C, Sashiwa H, Domb AJ (2004) Chitosan chemistry and pharmaceutical perspectives. Chem Rev 104: 6017-6084.

22. Jorfi M, Foster EJ (2015) Recent advances in nanocellulose for biomedical applications. J Appl Polym Sci 132: 41719.

23. Mizrahy S, Peer D (2012) Polysaccharides as building blocks for nanotherapeutics. Chem Soc Rev 41: 2623-2640.

24. Kemp MM, Linhardt RJ (2010) Heparin-based nanoparticles. Wiley Interdiscipl Rev Nanomed Nanobiotechnol 2: 77-87.

25. Swierczewska M, Han HS, Kim K, Park JH, Lee S (2016) Polysaccharidebased nanoparticles for theranostic nanomedicine. Adv Drug Deliv Rev 99: 70-84.

26. Goel S, Misra M, Saran R, Khana R (1998) The Rationale for and Role of Heparin in Peritoneal Dialysis. Adv Perit Dial 14: 111-115.

27. Rosett W, Hodges GR (1980) Antimicrobial activity of heparin. J Clin Microbiol 11: 30-34.

28. Tyrrell DJ, Horne AP, Holme KR, Preuss JM, Page CP (1999) Heparin in inflammation: potential therapeutic applications beyond anticoagulation. Adv Pharmacol 46: 151-208.

29. Deepa PR, Varalakshmi P (2003) Protective effect of low molecular weight heparin on oxidative injury and cellular abnormalities in adriamycin-induced cardiac and hepatic toxicity. Chem Biol Interact 146: 201-210.

30. Deepa PR, Varalakshmi P (2003) The cytoprotective role of a lowmolecular-weight heparin fragment studied in an experimental model of glomerulotoxicity. Eur J Pharmacol 478: 199-205. 